\title{
Effects of Force Field Selection on the Computational Ranking of MOFs for $\mathrm{CO}_{2}$ Separations
}

\author{
Derya Dokur and Seda Keskin*(i) \\ Department of Chemical and Biological Engineering, Koc University, Rumelifeneri Yolu, Sariyer, 34450 Istanbul, Turkey
}

Supporting Information

\begin{abstract}
Metal-organic frameworks (MOFs) have been considered as highly promising materials for adsorption-based $\mathrm{CO}_{2}$ separations. The number of synthesized MOFs has been increasing very rapidly. High-throughput molecular simulations are very useful to screen large numbers of MOFs in order to identify the most promising adsorbents prior to extensive experimental studies. Results of molecular simulations depend on the force field used to define the interactions between gas molecules and MOFs. Choosing the appropriate force field for MOFs is essential to make reliable predictions about the materials' performance. In this work, we performed two sets of molecular simulations using the two widely used generic force fields, Dreiding and UFF, and obtained adsorption data of $\mathrm{CO}_{2} / \mathrm{H}_{2}, \mathrm{CO}_{2} / \mathrm{N}_{2}$, and $\mathrm{CO}_{2} / \mathrm{CH}_{4}$ mixtures in 100 different MOF structures. Using this adsorption data, several adsorbent evaluation metrics including selectivity, working capacity, sorbent selection parameter, and percent regenerability were computed for each MOF. MOFs were then ranked based on these evaluation metrics, and top performing materials were identified. We then examined the sensitivity of the MOF rankings to the force field type. Our results showed that although there are significant quantitative differences between some adsorbent evaluation metrics computed using different force fields, rankings of the top MOF adsorbents for $\mathrm{CO}_{2}$ separations are generally similar: 8,8 , and 9 out of the top 10 most selective MOFs were found to be identical in the ranking for $\mathrm{CO}_{2} / \mathrm{H}_{2}, \mathrm{CO}_{2} / \mathrm{N}_{2}$, and $\mathrm{CO}_{2} / \mathrm{CH}_{4}$ separations using Dreiding and UFF. We finally suggested a force field factor depending on the energy parameters of atoms present in the MOFs to quantify the robustness of the simulation results to the force field selection. This easily computable factor will be highly useful to determine whether the results are sensitive to the force field type or not prior to performing computationally demanding molecular simulations.
\end{abstract}

\section{INTRODUCTION}

Metal organic frameworks (MOFs), composed of organic linkers connected by metal cations, offer high porosities, large surface areas, and good mechanical and chemical stabilities. ${ }^{1-3}$ These attractive physical and structural properties make MOFs strong alternatives to traditional adsorbents for $\mathrm{CO}_{2}$ capture. ${ }^{4}$ Several studies investigated adsorption-based $\mathrm{CO}_{2}$ separation performances of MOFs. ${ }^{5-8} \mathrm{~A}$ comparison of different porous adsorbents including MOFs, zeolites, and activated carbons shows that MOFs can outperform zeolites and carbon-based adsorbents due to their high $\mathrm{CO}_{2}$ selectivities and working capacities.' Combining various metals and organic linkers, thousands of MOFs have been synthesized to date with a large variety in geometries and chemical properties. Large numbers of MOFs offer both an opportunity and a challenge: It can be possible to find an ideal MOF adsorbent for a target $\mathrm{CO}_{2}$ separation process due the availability of many different materials. However, testing thousands of MOFs using purely experimental techniques at the lab scale is simply impractical. Molecular simulations have been successful to provide atomistic insights into gas adsorption and gas separation in MOFs. One of the contributions of molecular simulations is to screen a large number of MOFs in a time-effective manner to identify the most promising materials for desired applications to guide the experimental efforts, time, and resources to these promising materials. $^{10-13}$

The main and perhaps the most important input of molecular simulations of MOFs is a set of equations and parameters describing the physical and chemical interactions between gas molecules and MOFs. These equations and parameters together are known as force fields (FFs). The accuracy of a simulation strongly depends on the choice of the FF that describes gas-material interactions. Therefore, using accurate FFs in molecular simulation of materials is essential to make reliable predictions about the materials' performances. At the early stages of the molecular simulation studies of MOFs, efforts have been made to develop new FFs specific to gasMOF interactions using quantum-level calculations. ${ }^{14,15}$ These calculations are computationally demanding; therefore, they can be performed for a very small number of MOFs but not for large-scale screening of materials. Some studies refined the generic FF parameters to better match the predictions of molecular simulations with the available experimental measure-

Received: November 20, 2017

Revised: January 17, 2018

Accepted: January 18, 2018

Published: January 18, 2018 
ments of gas adsorption in MOFs. ${ }^{16,17}$ However, experimental studies focused on a small group of materials among thousands of available MOFs and many materials are lacking the experimentally measured gas adsorption isotherm data that can be used to validate the FF.

Due to these reasons, it is challenging and computationally very demanding to develop a new FF applicable to all kinds of MOFs. As a result, two off-the-shelf, generic FFs, Universal Force Field (UFF) ${ }^{18}$ and Dreiding, ${ }^{19}$ are very widely used in molecular simulations of MOFs. Several studies compared the results of molecular simulations employing either UFF or Dreiding with the experimentally measured gas uptake data of MOFs and showed good agreement between experiments and simulations, validating the usage of these two FFs for MOFs. ${ }^{10}$ The $\mathrm{CO}_{2}$ adsorption isotherms of 424 hypothetical MOFs were recently computed using both the UFF and an $a b$ initio FF. ${ }^{20}$ Results showed that there are significant quantitative differences between the $\mathrm{CO}_{2}$ uptakes predicted by the generic FF and the $a b$ initio FF. In spite of these quantitative differences in $\mathrm{CO}_{2}$ uptakes, a good correlation was reported between the relative rankings of MOFs in terms of absolute $\mathrm{CO}_{2}$ uptake capacities predicted by different FFs. It was concluded that it may be a reasonable approximation to employ UFF in identifying the top percentage of MOFs for a particular gas adsorption application, but caution is still warranted. At that point, it is important to note that there are also examples of where UFF and Dreiding may fail in predicting gas adsorption data of MOFs. For example, Smit's group ${ }^{21}$ reported that common FFs typically underestimate the $\mathrm{CO}_{2}$ adsorption in Mg-MOF-74, which has open metal sites, and presented a novel methodology that gives accurate FFs for $\mathrm{CO}_{2}$ and $\mathrm{N}_{2}$ adsorption in this MOF from high-level quantum chemical calculations. These FFs were defined to account for the subtle changes in the chemical environment induced by the presence of open metal sites in MOFs. Boyd et al. ${ }^{22}$ recently evaluated the bulk properties of several MOFs using generic FFs and showed that UFF and Dreiding provide good values for the bulk modulus and linear thermal expansion coefficients of these materials. FFs that are specifically developed for MOFs such as UFF4MOF were also reported to provide accurate values for these materials' properties. They concluded that each FF offers a moderately good picture of these properties.

The role of FF selection on the predicted mixture adsorption in MOFs can be much more important than the one on the single-component gas uptake because of the competitive interactions between different gas species of a mixture for the same adsorption site of a MOF. Dreiding and UFF have been commonly used in large-scale screening of MOF adsorbents. For example, Watanabe and Sholl ${ }^{23}$ used Dreiding in their molecular simulations and reported the $\mathrm{CO}_{2} / \mathrm{N}_{2}$ selectivity of 359 MOFs. Wu et al. ${ }^{24}$ studied separation of $\mathrm{CO}_{2} / \mathrm{N}_{2}$ mixtures in $105 \mathrm{MOF}$ using Dreiding. Qiao et al. ${ }^{25}$ recently reported a molecular simulation study that employs UFF to study MOFs for $\mathrm{CO}_{2}$ separation from flue gas and natural gas. We recently performed molecular simulations to compute adsorption-based $\mathrm{CO}_{2} / \mathrm{H}_{2}, \mathrm{CO}_{2} / \mathrm{N}_{2}$, and $\mathrm{CO}_{2} / \mathrm{CH}_{4}$ separation performances of 100 representative MOFs. ${ }^{26}$ In our simulations, UFF was used for $28 \mathrm{MOFs}$, and Dreiding was employed for $72 \mathrm{MOFs}$ based on the agreement between the simulation results and available experimental gas uptake data of MOFs. These MOFs were then ranked using several adsorbent performance evaluation metrics such as selectivity and regenerability which were calculated using the mixture adsorption data obtained from the molecular simulations. However, the impact of FF type on the predicted gas separation performances of MOF adsorbents and their rankings has not been explored to date. Considering the ongoing research on high-throughput molecular simulations of MOFs for adsorption and separation of various gas mixtures, it is important to examine the robustness of adsorbents rankings with respect to the FF type.

In this work, we performed molecular simulations to compare the results from two different generic FFs, Dreiding and UFF, by computing adsorption of $\mathrm{CO}_{2} / \mathrm{H}_{2}, \mathrm{CO}_{2} / \mathrm{N}_{2}$, and $\mathrm{CO}_{2} / \mathrm{CH}_{4}$ mixtures in 100 different MOF structures. Using the gas adsorption data, four adsorbent evaluation metrics, adsorption selectivity, working capacity, sorbent selection parameter, percent regenerability were computed for each MOF and for each gas separation. The metrics obtained from molecular simulations using different FFs were first compared to understand their sensitivities to the FF type. MOFs were then ranked based on these performance evaluation metrics to identify the top 10 best materials for separation of $\mathrm{CO}_{2} / \mathrm{H}_{2}$, $\mathrm{CO}_{2} / \mathrm{N}_{2}$, and $\mathrm{CO}_{2} / \mathrm{CH}_{4}$ mixtures. The MOFs that appear in the highly promising materials list of Dreiding and UFF-based molecular simulations were compared and the robustness of the material rankings with respect to the FF type was discussed. At that point, it is important to note that we did not intend to examine the accuracy of these FFs, because both Dreiding and UFF were previously used to predict the $\mathrm{CO}_{2}$ uptakes of various MOFs and comparison with the experimentally measured gas adsorption data showed that both are good in capturing the adsorption isotherms. ${ }^{26,27}$ We mainly aimed to define "a safe region" for MOFs in which using either Dreiding or UFF will not lead to significantly different results about the gas separation performance of a material. With this motivation, we proposed a force field factor, depending on the number and type of the atoms present in the MOF and their corresponding energy parameters. We showed that if this easily computable factor is low then either the Dreiding or UFF can be used to estimate the $\mathrm{CO}_{2}$ uptake and $\mathrm{CO}_{2}$ separation performance of the MOF. This factor will be highly useful to guide the simulators about the sensitivity of the predictions for the $\mathrm{CO}_{2}$ uptake of MOFs to the FF type prior to performing computationally demanding molecular simulations.

\section{COMPUTATIONAL DETAILS}

We considered the same $100 \mathrm{MOF}$ that were studied in our previous work ${ }^{26}$ to have a representative structural database that spans a wide range of chemical functionalities. Crystal structures of all MOFs were taken from the Cambridge Crystallographic Data Centre (CCDC). ${ }^{28}$ The complete list of the materials with CCDC names and structural properties such as pore limiting diameter (PLD), largest cavity diameter (LCD), pore volume, porosity, and surface area of the MOFs can be also found in our previous report. ${ }^{26}$ We used Grand Canonical Monte Carlo (GCMC) ${ }^{29}$ simulations to compute adsorption isotherms of binary gas mixtures, $\mathrm{CO}_{2} / \mathrm{H}_{2}, \mathrm{CO}_{2} / \mathrm{N}_{2}$, and $\mathrm{CO}_{2} / \mathrm{CH}_{4}$ in MOFs. In a GCMC simulation, adsorbed amounts of each gas component were calculated by specifying the bulk pressure, temperature, and composition of the bulk gas mixtures. Five different types of moves were considered for GCMC simulations of gas mixtures including translation, rotation, insertion, deletion, and exchange of molecules. The Lorentz-Berthelot mixing rules were employed. The cutoff distance for truncation of the intermolecular interactions was set to $13 \AA$. Periodic boundary conditions were applied in all 
simulations. A simulation box of $2 \times 2 \times 2$ crystallographic unit cells was used. During the simulations, $1.5 \times 10^{7}$ steps were performed to guarantee the equilibration and $1.5 \times 10^{7}$ steps were performed to sample the desired properties. Rigid framework assumption was used in all simulations following the literature $\mathrm{r}^{30-32}$ and the good agreement between the results of simulations using rigid framework and the experimentally measured gas adsorption data was shown in our previous work. $^{26}$

Molecular simulations were first performed using Dreiding and then repeated under the same conditions using the UFF. These two FFs are widely used in simulations of MOFs for gas adsorption because they offer the advantage of being adaptable to many chemical environments. Dreiding is a generic FF developed back in 1990 to predict structures and dynamics of organic, biological, and main group inorganic molecules. ${ }^{19}$ UFF was introduced in 1992 as a full periodic table FF where the parameters were estimated using general rules based on the element, its hybridization and its connectivity. ${ }^{18}$ For some metal atoms of the MOFs, such as $\mathrm{Ag}, \mathrm{Be}, \mathrm{Cd}, \mathrm{Co}, \mathrm{Cu}, \mathrm{Fe}, \mathrm{Mn}$, $\mathrm{Nd}, \mathrm{Ni}$, and $\mathrm{Zr}$, potential parameters are not available in the Dreiding FF. These parameters were taken from the UFF. Potential parameters of the MOF atoms in UFF and Dreiding are given in Table S1. It is important to note that we showed very good agreement between our simulation results and experimentally measured $\mathrm{CH}_{4}, \mathrm{H}_{2}, \mathrm{~N}_{2}$, and $\mathrm{CO}_{2}$ adsorptions in many MOFs in our previous works. ${ }^{26,33,34}$ For example, we showed the accuracy of our simulations by comparing simulated $\mathrm{CH}_{4}$ adsorption of MOFs with 267 experimental data at a variety of pressures and temperatures. ${ }^{33}$ Similarly, the good agreement between simulated $\mathrm{H}_{2}$ adsorption and the experimentally reported data of a variety of MOFs including many subfamilies such as IRMOFs, PCNs, and ZIFs was shown. ${ }^{34}$ Good agreements between experimental and simulated data of $\mathrm{CO}_{2}$ adsorption in a large number of MOFs such as IRMOF-1, IRMOF-3, MOF-14, ZIF-8, ZIF-68, ZIF-79, CuBTC was shown in our recent work. ${ }^{26}$ We also demonstrated the good agreement between experimentally reported $\mathrm{CO}_{2} / \mathrm{CH}_{4}, \mathrm{CO}_{2} / \mathrm{N}_{2}$ and $\mathrm{CO}_{2} / \mathrm{H}_{2}$ selectivities of various MOF groups including IRMOFs, ZIFs, MILs, MOF-74 series and our simulation data in Figure $S 1$ to validate the accuracy of our molecular simulations in estimating the MOF adsorbents' selectivities.

Gas molecules were modeled using Lennard-Jones (LJ) potentials. A three-site rigid molecule with LJ 12-6 potential was used to model $\mathrm{CO}_{2}$ and locations of the partial point charges were set as center of each site. ${ }^{35} \mathrm{~N}_{2}$ was also modeled as a three-site molecule: Two sites were located at the $\mathrm{N}$ atoms, and the third site was located at the center of the mass with partial point charges. ${ }^{36} \mathrm{H}_{2}{ }^{37}$ and $\mathrm{CH}_{4}{ }^{38}$ were modeled by using single-site spherical LJ 12-6 potentials. Electrostatic interactions were taken into consideration using the Coulomb potential for gas molecules with multipole moments, $\mathrm{CO}_{2}$ and $\mathrm{N}_{2}$. The cutoff distance for truncation of electrostatic interactions was set to $25 \AA$. In order to compute the electrostatic interactions between gas molecules and MOFs, partial point charges were assigned to MOF atoms using extended charge equilibration method (EQeq). ${ }^{39}$ A recent study examined the impact of atomic charge assignment methods of MOFs on the high-throughput computational screening for $\mathrm{CO}_{2} / \mathrm{H}_{2} \mathrm{O}$ separations and found that the majority of the top MOFs are identical regardless of the charge assignment method. ${ }^{40}$
Adsorption data of gas mixtures obtained from the GCMC simulations were used to compute several adsorbent evaluation metrics, namely adsorption selectivity $(S)$, working capacity $(\Delta N)$, sorbent selection parameter $\left(S_{\mathrm{sp}}\right)$, and percent regenerability $(R \%)$. Calculation details of these metrics are given in Table 1 . In these equations, $x(y)$ represents the

Table 1. Adsorbent Evaluation Metrics Used in Ranking of MOFs

\begin{tabular}{lc}
\multicolumn{1}{c}{ metrics } & calculation \\
selectivity & $S_{\mathrm{ads}(1 / 2)}=\frac{x_{1} / x_{2}}{y_{1} / y_{2}}$ \\
working capacity $(\mathrm{mol} / \mathrm{kg})$ & $\Delta N=N_{\mathrm{ads}}-N_{\mathrm{des}}$ \\
sorbent selection parameter & $S_{\mathrm{sp}}=\frac{\left(S_{\mathrm{ads}(1 / 2)}\right)^{2}}{\left(S_{\mathrm{des}(1 / 2)}\right)} \times \frac{\Delta N_{1}}{\Delta N_{2}}$ \\
percent regenerability $(\%)$ & $R \%=\frac{\Delta N_{1}}{N_{1, \mathrm{ads}}} \times 100 \%$ \\
\hline
\end{tabular}

compositions of the adsorbed (bulk) gases in the adsorbent, and $N_{\text {ads }}$ and $N_{\text {des }}$ are the gas uptakes at the adsorption and desorption pressures, respectively. Subscript 1 (2) represents strongly (weakly) adsorbed gas. In our study, component 1 is always $\mathrm{CO}_{2}$ and component 2 is either $\mathrm{H}_{2}, \mathrm{~N}_{2}$, or $\mathrm{CH}_{4}$ depending on the mixture. All calculations were performed at an adsorption pressure of 1 bar and desorption pressure of 0.1 bar at $298 \mathrm{~K}$. Compositions of the binary gas mixtures were set as $\mathrm{CO}_{2} / \mathrm{H}_{2}: 15 / 85, \mathrm{CO}_{2} / \mathrm{N}_{2}: 15 / 85$, and $\mathrm{CO}_{2} / \mathrm{CH}_{4}: 50 / 50$ in molecular simulations to mimic industrial operating conditions. The operating conditions and gas compositions were specifically chosen to represent the landfill gas separation $\left(\mathrm{CO}_{2} / \mathrm{CH}_{4}\right)$ and flue gas separation $\left(\mathrm{CO}_{2} / \mathrm{N}_{2}\right)$ using vacuum swing adsorption following the literature. ${ }^{41}$

\section{RESULTS AND DISCUSSION}

Selectivity is generally considered as the primary metric in ranking adsorbent materials. An adsorbent with high selectivity is accepted as promising in gas separation applications. Therefore, we first computed selectivities of MOFs for $\mathrm{CO}_{2} /$ $\mathrm{H}_{2}, \mathrm{CO}_{2} / \mathrm{N}_{2}$, and $\mathrm{CO}_{2} / \mathrm{CH}_{4}$ mixtures at 1 bar and $298 \mathrm{~K}$ using the mixture adsorption data obtained from the GCMC simulations. The $\mathrm{CO}_{2}$ selectivities of MOFs computed from molecular simulations employing Dreiding and UFF are compared in Figure 1 for three gas mixtures. Comparison of selectivities obtained from two sets of molecular simulations using different FFs is also separately given for $\mathrm{CO}_{2} / \mathrm{H}_{2}, \mathrm{CO}_{2} /$ $\mathrm{N}_{2}$, and $\mathrm{CO}_{2} / \mathrm{CH}_{4}$ mixtures in Figures $\mathrm{S} 2-\mathrm{S} 4$, respectively. The $\mathrm{CO}_{2}$ selectivities calculated with Dreiding (UFF) are in the ranges of $10.48-2237.35(12.38-3119.09), 3.73-202.30$ (3.75-197.48), and 1.66-59.38 (1.71-60.97) for $\mathrm{CO}_{2} / \mathrm{H}_{2}$, $\mathrm{CO}_{2} / \mathrm{N}_{2}$, and $\mathrm{CO}_{2} / \mathrm{CH}_{4}$ mixtures, respectively. Figure 1 shows that molecular simulations with UFF led to slightly higher selectivities for $\mathrm{CO}_{2} / \mathrm{H}_{2}$ mixtures compared to the ones with Dreiding. Selectivities calculated for $\mathrm{CO}_{2} / \mathrm{N}_{2}$ and $\mathrm{CO}_{2} / \mathrm{CH}_{4}$ mixtures were similar for most MOFs regardless of the FF type. In extreme cases, using UFF can give 2.2, 1.6, and 1.7 times larger $\mathrm{CO}_{2} / \mathrm{H}_{2}, \mathrm{CO}_{2} / \mathrm{N}_{2}$, and $\mathrm{CO}_{2} / \mathrm{CH}_{4}$ selectivities than using the Dreiding FF. For example, $\mathrm{CO}_{2} / \mathrm{H}_{2}$ selectivity of a MOF, LASPOM, was predicted as 205.59 by Dreiding and 441.25 by UFF, leading to a large difference of $114.63 \%$. The largest deviations for $\mathrm{CO}_{2} / \mathrm{N}_{2}$ and $\mathrm{CO}_{2} / \mathrm{CH}_{4}$ selectivities were 


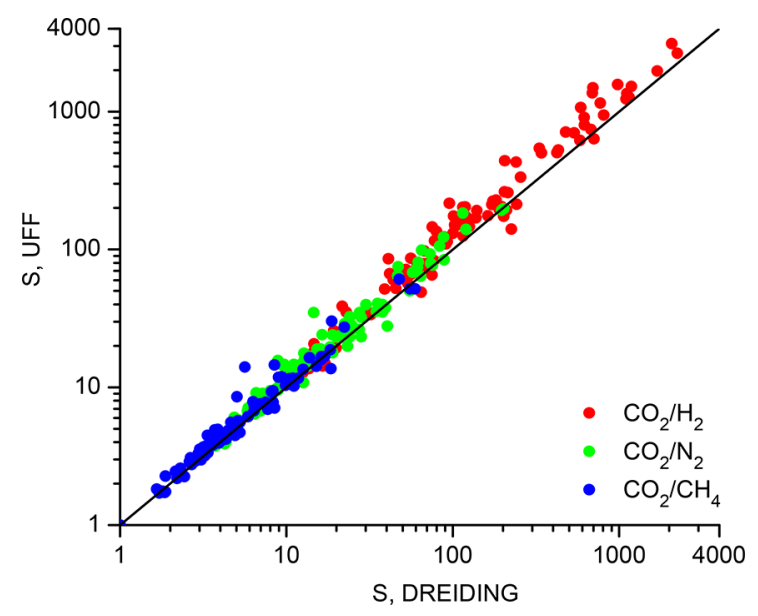

Figure 1. Comparison of selectivities of MOFs computed using Dreiding and UFF for $\mathrm{CO}_{2} / \mathrm{H}_{2}, \mathrm{CO}_{2} / \mathrm{N}_{2}, \mathrm{CO}_{2} / \mathrm{CH}_{4}$ separations. Diagonal line is to guide the eye.

observed for OCIZIL and LUXDEO, respectively. The $\mathrm{CO}_{2} /$ $\mathrm{N}_{2}\left(\mathrm{CO}_{2} / \mathrm{CH}_{4}\right)$ selectivity of the relevant MOF was predicted as 47.00 (8.45) by Dreiding and 75.10 (14.54) by UFF, resulting in $59.77 \%(71.97 \%)$ difference. The discrepancies originated from using different FFs can be explained with the changes in the energy parameters of MOF atoms. For example, OCIZIL has $\mathrm{Zn}$ as the metal atom and the energy parameter of
Zn significantly increases when the UFF was used instead of Dreiding $\left(\varepsilon_{\text {Zn,Dreiding }} / k_{\mathrm{B}}=27.69 \mathrm{~K}, \varepsilon_{\mathrm{Zn}, \mathrm{UFF}} / k_{\mathrm{B}}=62.44 \mathrm{~K}\right)$ in simulations. As a result, adsorption of $\mathrm{CO}_{2}$ increases and more pronounced deviations are observed for the $\mathrm{CO}_{2}$ selectivity. Overall, Figure 1 shows that both Dreiding and UFF can be used in the molecular simulations for the initial screening of MOF adsorbents based on selectivity, however caution is advised especially for $\mathrm{CO}_{2} / \mathrm{H}_{2}$ mixtures where the selectivity predictions of Dreiding and UFF may significantly vary. At that point, it is important to note that the MOFs we considered in this work have metal atoms of $\mathrm{Ag}, \mathrm{Al}, \mathrm{Be}, \mathrm{Cd}, \mathrm{Co}, \mathrm{Cu}, \mathrm{Fe}, \mathrm{In}$, $\mathrm{Mn}, \mathrm{Nd}, \mathrm{Ni}, \mathrm{V}, \mathrm{Zn}$, and $\mathrm{Zr}$. Among these, $\mathrm{Al}$, In, and $\mathrm{Zn}$ have different energy parameters in Dreiding and UFF. The change in the energy parameters of $\mathrm{Zn}$ is the highest as can be seen from Table S1. For example, the energy parameters of In in the UFF and Dreiding are very close $\left(\varepsilon_{\mathrm{In}, \text { Dreiding }} / k_{\mathrm{B}}=276.96 \mathrm{~K}\right.$, $\left.\varepsilon_{\text {In,UFF }} / k_{\mathrm{B}}=301.63 \mathrm{~K}\right)$. Although there are changes in the energy parameters, the correlation coefficients $\left(R^{2}\right)$ between the predictions of Dreiding and UFF for the selectivities of MOFs containing $\mathrm{Al}$, In, and $\mathrm{Zn}$ were computed to be not very different $\left(0.97,0.95\right.$, and 0.89 for $\mathrm{CO}_{2} / \mathrm{H}_{2}, \mathrm{CO}_{2} / \mathrm{N}_{2}$, and $\mathrm{CO}_{2} /$ $\mathrm{CH}_{4}$ mixtures, respectively) than the $\mathrm{R}^{2}$ values $(0.96,0.94$, and 0.94 for $\mathrm{CO}_{2} / \mathrm{H}_{2}, \mathrm{CO}_{2} / \mathrm{N}_{2}$, and $\mathrm{CO}_{2} / \mathrm{CH}_{4}$ mixtures, respectively) computed for $\mathrm{MOF}$ that contain other metals.

Since selectivity solely depends on the gas uptakes of MOFs, we examined the role of the FF type on the gas uptakes of MOFs. Among the four gases we considered, $\mathrm{CO}_{2}$ is the most
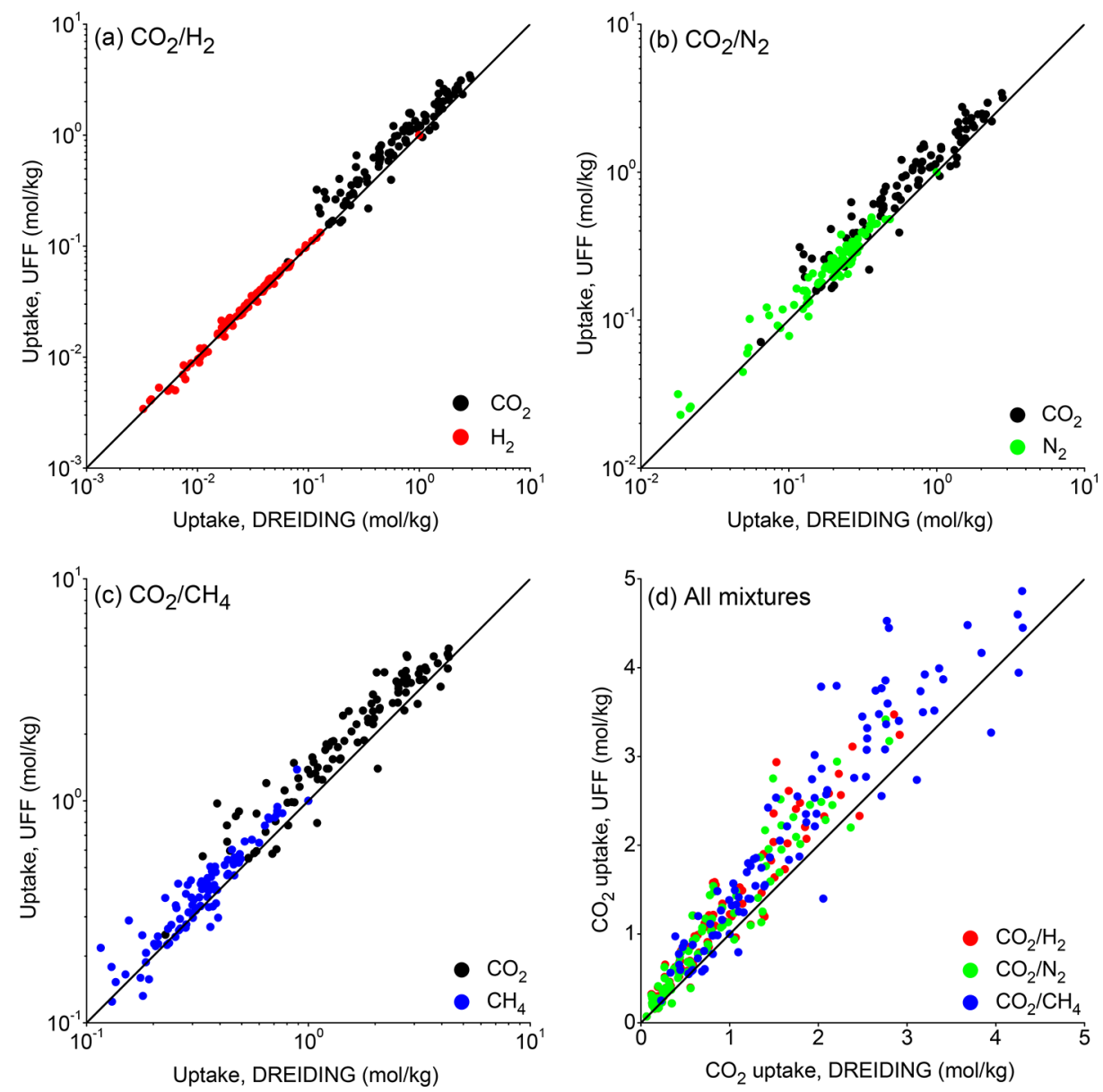

Figure 2. Comparison of gas uptakes of MOFs computed using Dreiding and UFF for (a) $\mathrm{CO}_{2} / \mathrm{H}_{2}$, (b) $\mathrm{CO}_{2} / \mathrm{N}_{2},(\mathrm{c}) \mathrm{CO}_{2} / \mathrm{CH}_{4}$, and (d) all mixtures. Diagonal lines are to guide the eye. 
Table 2. Correlation Coefficients $\left(R^{2}\right)$ for the Gas Uptakes Predicted by Dreiding and UFF

\begin{tabular}{|c|c|c|c|c|c|c|c|c|}
\hline & \multicolumn{2}{|c|}{$\mathrm{CO}_{2}$ uptake $(\mathrm{mol} / \mathrm{kg})$} & \multicolumn{2}{|c|}{$\mathrm{H}_{2}$ uptake $(\mathrm{mol} / \mathrm{kg})$} & \multicolumn{2}{|c|}{$\mathrm{N}_{2}$ uptake $(\mathrm{mol} / \mathrm{kg})$} & \multicolumn{2}{|c|}{$\mathrm{CH}_{4}$ uptake $(\mathrm{mol} / \mathrm{kg})$} \\
\hline & 0.1 bar & $1 \mathrm{bar}$ & $0.1 \mathrm{bar}$ & $1 \mathrm{bar}$ & $0.1 \mathrm{bar}$ & $1 \mathrm{bar}$ & 0.1 bar & $1 \mathrm{bar}$ \\
\hline $\mathrm{CO}_{2} / \mathrm{H}_{2}$ & 0.9419 & 0.9177 & 0.9914 & 0.9952 & & & & \\
\hline $\mathrm{CO}_{2} / \mathrm{N}_{2}$ & 0.9403 & 0.9179 & & & 0.9268 & 0.9136 & & \\
\hline $\mathrm{CO}_{2} / \mathrm{CH}_{4}$ & 0.9408 & 0.8813 & & & & & 0.8404 & 0.9293 \\
\hline
\end{tabular}
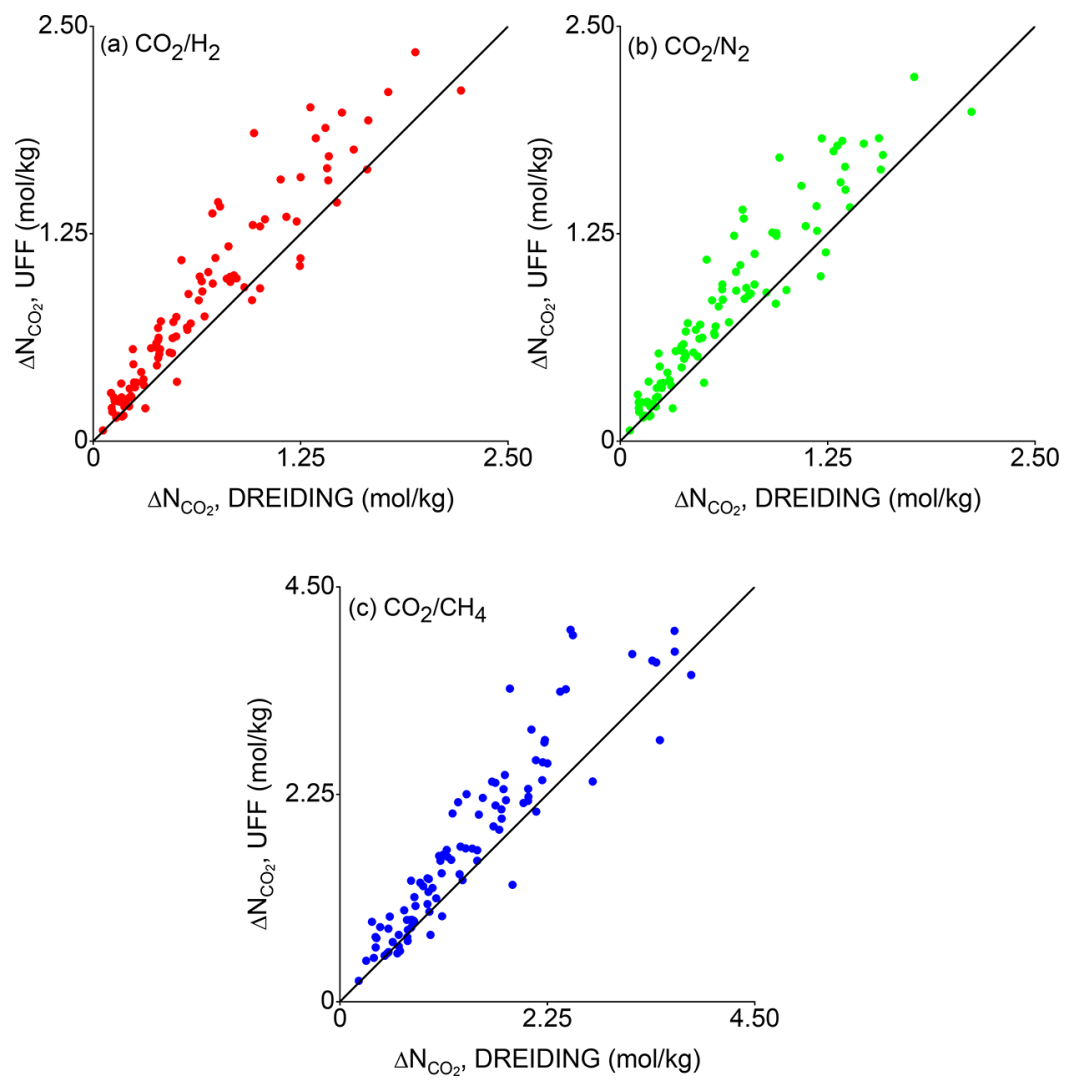

Figure 3. Comparison of the $\mathrm{CO}_{2}$ working capacities of MOFs computed using Dreiding and UFF for (a) $\mathrm{CO}_{2} / \mathrm{H}_{2},(\mathrm{~b}) \mathrm{CO}_{2} / \mathrm{N}_{2}$, and (c) $\mathrm{CO}_{2} / \mathrm{CH}_{4}$ mixtures. Diagonal lines are to guide the eye.

strongly adsorbed component. It was represented as a three-site molecule which has more interactions sites with the MOF atoms compared to other gases in addition to the electrostatic interactions due to its quadrupole moment. $\mathrm{H}_{2}$ has very weak interactions with MOFs leading to very low uptakes. Figure 2 shows that molecular simulations performed at 1 bar using UFF generally result in higher uptakes for $\mathrm{CO}_{2}, \mathrm{CH}_{4}$ and $\mathrm{N}_{2}$ compared to the ones performed using Dreiding. This result is more pronounced for $\mathrm{CO}_{2}$, followed by $\mathrm{CH}_{4}$ and $\mathrm{N}_{2}$, as can be seen in Figures $\mathrm{S} 5-\mathrm{S} 7$ where uptakes for each gas species are separately shown. The $\mathrm{CO}_{2}$ uptakes of MOFs for $\mathrm{CO}_{2} / \mathrm{H}_{2}$, $\mathrm{CO}_{2} / \mathrm{N}_{2}$, and $\mathrm{CO}_{2} / \mathrm{CH}_{4}$ mixtures were computed as $0.07-2.92$ (0.07-3.47), 0.06-2.80 (0.07-3.42), and 0.23-4.30 (0.25$4.86) \mathrm{mol} / \mathrm{kg}$, respectively using the Dreiding (UFF). The $\mathrm{H}_{2}$ uptakes of MOFs were calculated to be almost same, 0.003$0.13 \mathrm{~mol} / \mathrm{kg}$, regardless of the FF type. The correlation coefficient $\left(R^{2}\right)$ was defined as a linear fit between the Dreiding predicted results and UFF predicted results. The $R^{2}$ between the predictions of Dreiding and UFF for the gas uptakes of MOFs computed at 1 bar are given in Table 2. The $R^{2}$ values also show that $\mathrm{CO}_{2}$ is the component which is more sensitive to the FF type, followed by $\mathrm{N}_{2}$ and $\mathrm{CH}_{4}$, whereas $\mathrm{H}_{2}$ uptakes do not change with the FF. Since UFF-based simulations overpredicted the $\mathrm{N}_{2}$ and $\mathrm{CH}_{4}$ uptakes of MOFs in similar amounts compared to the $\mathrm{CO}_{2}$ uptake, $\mathrm{CO}_{2} / \mathrm{N}_{2}$ and $\mathrm{CO}_{2} / \mathrm{CH}_{4}$ selectivities predicted by two $\mathrm{FFs}$ were not significantly different as previously shown in Figure 1. The $\mathrm{CO}_{2}$ uptakes predicted by UFF were higher than those of Dreiding but almost same for $\mathrm{H}_{2}$. As a result, UFF-based simulations give much larger $\mathrm{CO}_{2} / \mathrm{H}_{2}$ selectivities than those of the Dreidingbased ones. These results indicate that the more strongly adsorbed component in MOFs, in our case $\mathrm{CO}_{2}$, is more sensitive to the type of the FF used in the simulations compared to the weakly adsorbed gases. In other words, if the adsorption competition between two gas molecules is low, such as $\mathrm{CO}_{2}$ and $\mathrm{H}_{2}$, then selectivities predicted by two different FFs can be significantly different.

Working capacity is generally considered as the second most important metric used to evaluate new adsorbent materials. Figure 3 represents the predicted $\mathrm{CO}_{2}$ working capacities of MOFs at an adsorption pressure of 1 bar and desorption pressure of 0.1 bar. Detailed comparison of $\mathrm{CO}_{2}$ uptakes of MOFs at 0.1 and 1 bar using Dreiding and UFF can be found in Figures $\mathrm{S} 8-\mathrm{S} 10$ for all three mixtures. Similar to the $\mathrm{CO}_{2}$ uptakes, $\mathrm{CO}_{2}$ working capacities predicted by UFF generally overestimated the predictions of Dreiding. Table 3 shows that 
Table 3. Correlation Coefficients $\left(R^{2}\right)$ for the Performance Evaluation Metrics Predicted by Dreiding and UFF for Each Gas Mixture

\begin{tabular}{lcccc} 
& $S$ & $\Delta N_{\mathrm{CO}_{2}}(\mathrm{~mol} / \mathrm{kg})$ & $S_{\mathrm{sp}}$ & $R \%$ \\
$\mathrm{CO}_{2} / \mathrm{H}_{2}$ & 0.9528 & 0.8928 & 0.9674 & 0.9378 \\
$\mathrm{CO}_{2} / \mathrm{N}_{2}$ & 0.9434 & 0.8936 & 0.9552 & 0.9377 \\
$\mathrm{CO}_{2} / \mathrm{CH}_{4}$ & 0.9408 & 0.8648 & 0.9105 & 0.9549 \\
\hline
\end{tabular}

$R^{2}$ values of the working capacities $(0.86-0.89)$ are lower than those of selectivities (0.94-0.95), indicating that working capacity is much more sensitive to the FF type than the selectivity. Combining selectivity and working capacity in a single parameter, $S_{\mathrm{sp}}$ is useful to easily identify the most promising adsorbents. We compared $S_{\mathrm{sp}}$ values of MOFs using the results of simulations employing Dreiding and UFF in Figure 4. The $S_{\mathrm{sp}}$ values of MOFs for $\mathrm{CO}_{2} / \mathrm{H}_{2}, \mathrm{CO}_{2} / \mathrm{N}_{2}$, and $\mathrm{CO}_{2} / \mathrm{CH}_{4}$ separations were calculated as $19.34-3.9 \times 10^{5}$ $\left(26.74-6.9 \times 10^{5}\right), 2.51-5178.36(2.54-8980.72)$, and $2.91-$ $2276.69\left(3.02-1.07 \times 10^{4}\right)$, respectively using the Dreiding (UFF). These numbers indicate that quantitative predictions of molecular simulations for $S_{\text {sp }}$ strongly depend on the FF type. This is in fact a natural result of the mathematical description of $S_{\text {sp. }}$. It includes the square of the selectivity, and as we discussed in Figure 1, there are several MOFs for which UFF-based simulations predicted double of the $\mathrm{CO}_{2}$ selectivities compared to the Dreiding-based simulations. As a result, there are MOFs for which using UFF gives 1.73, 1.73, and 4.70 times higher $S_{\mathrm{sp}}$ values than using Dreiding for $\mathrm{CO}_{2} / \mathrm{H}_{2}, \mathrm{CO}_{2} / \mathrm{N}_{2}$, and $\mathrm{CO}_{2} /$ $\mathrm{CH}_{4}$ separations, respectively.
We finally examined the impact of FF on the predicted percent regenerabilities $(R \%)$ of MOFs. Although MOF adsorbents are used to be ranked based on selectivity, our recent study showed that it is much more efficient to screen MOFs based on $R \%$ because a large number of MOFs having high $\mathrm{CO}_{2}$ selectivities suffers from very low $R \%(<75 \%){ }^{26}$ Figure 5 shows that R\% of MOFs ranges from 48.83 to $90.64 \%$ (44.32-91.12\%) for $\mathrm{CO}_{2} / \mathrm{H}_{2}$ separation based on the molecular simulations performed using Dreiding (UFF). $R \%$ is defined as the ratio of working capacity to the gas uptake at an adsorption pressure. Since overestimation of UFF for $\mathrm{CO}_{2}$ uptake is higher than the one for the $\mathrm{CO}_{2}$ working capacity, $\mathrm{R} \%$ predictions of UFF are generally lower than those of Dreiding. $R \%$ of MOFs ranges from 46.32 to $90.47 \%$ (33.52-91.48\%) for $\mathrm{CO}_{2} / \mathrm{N}_{2}\left(\mathrm{CO}_{2} / \mathrm{CH}_{4}\right)$ separation based on the molecular simulations performed using Dreiding whereas UFF results are slightly less, $44.39-90.83 \%$ (26.37-91.68\%). Similar to the selectivity, the $R^{2}$ values for $R \%(0.94-0.95)$ are high, as shown in Table 3, although sometimes large quantitative deviations were observed in the predicted $R \%$ values from two different FFs.

$R^{2}$ values calculated for all the adsorbent evaluation metrics can be seen in Table 3 . The $R^{2}$ values are high $(>0.86)$ for all four metrics suggesting that both FFs make quantitatively similar estimates for the four performance evaluation metrics that we discussed. Therefore, we also examined how the rankings of best MOF adsorbents change with Dreiding and UFF. The top 10 MOFs rankings based on the four performance evaluation metrics computed from two different FFs are listed in Table 4. According to the $\mathrm{CO}_{2} / \mathrm{H}_{2}$ selectivity ranking, there are 8 common MOFs in the top promising

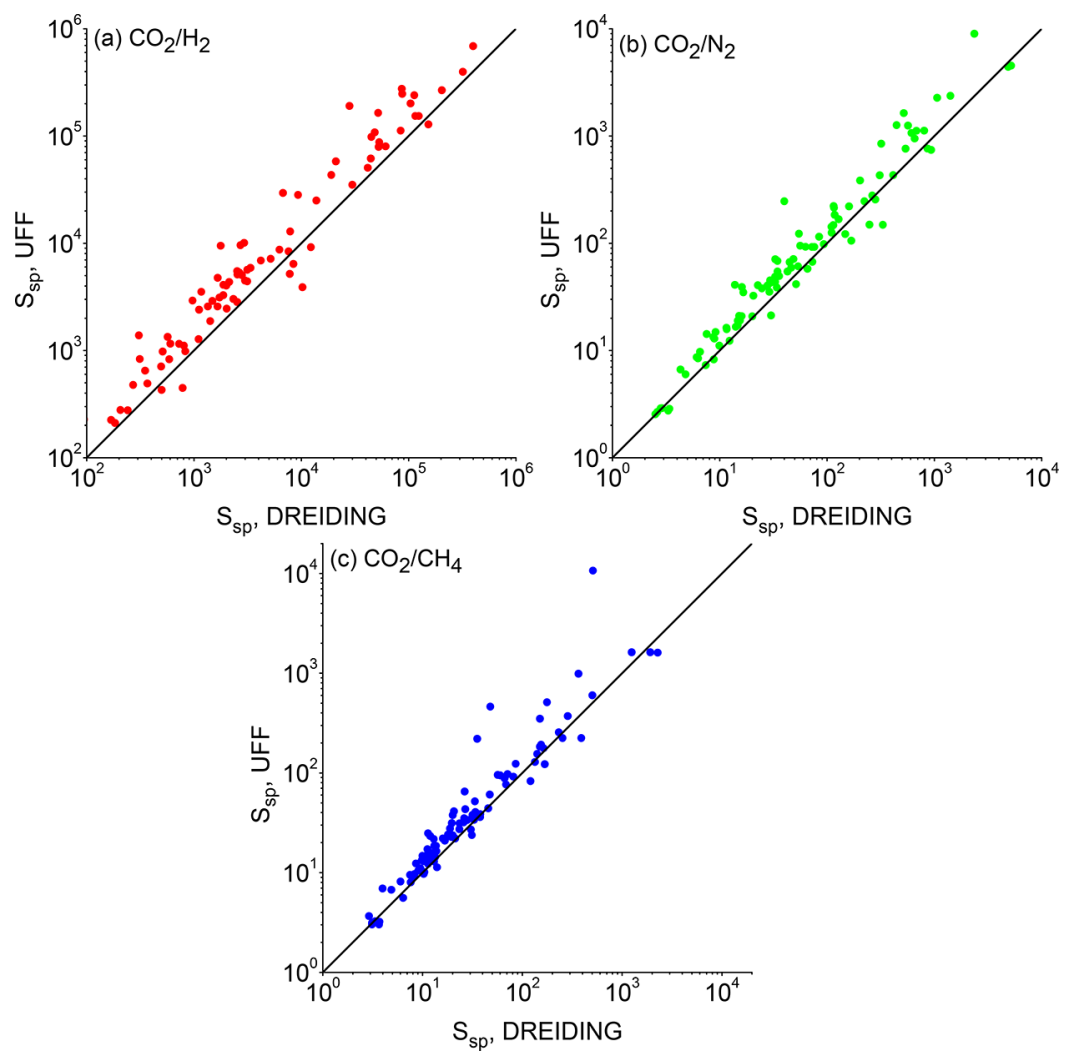

Figure 4. Comparison of sorbent selection parameters of MOFs computed using Dreiding and UFF for (a) $\mathrm{CO}_{2} / \mathrm{H}_{2},(b) \mathrm{CO}_{2} / \mathrm{N}_{2}$, and (c) $\mathrm{CO}_{2} /$ $\mathrm{CH}_{4}$ mixtures. Diagonal lines are to guide the eye. 


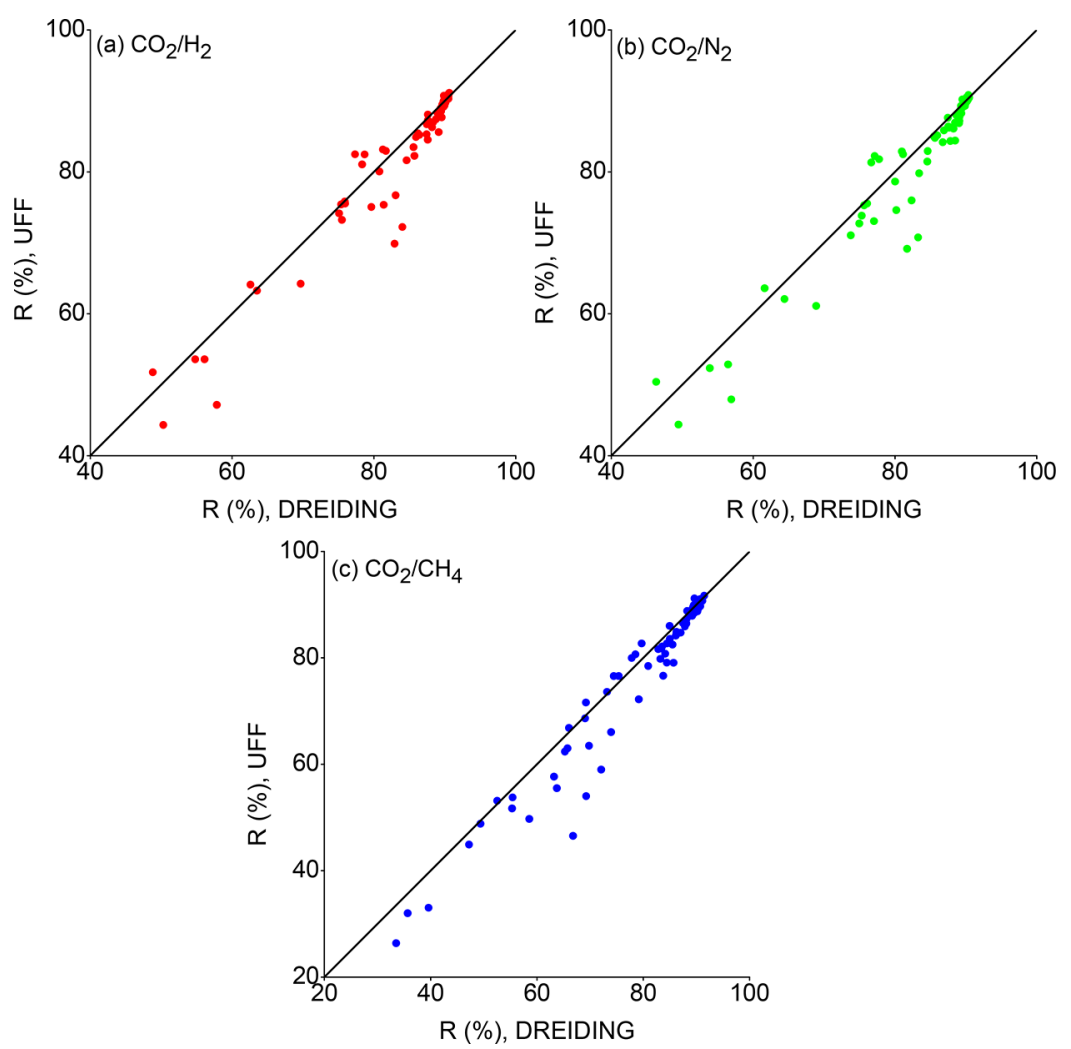

Figure 5. Comparison of percent regenerabilities of MOFs computed using Dreiding and UFF for (a) $\mathrm{CO}_{2} / \mathrm{H}_{2},(\mathrm{~b}) \mathrm{CO}_{2} / \mathrm{N}_{2}$, and (c) $\mathrm{CO}_{2} / \mathrm{CH}_{4}$ mixtures. Diagonal lines are to guide the eye.

material lists of Dreiding and UFF. Ranking of the materials is very similar. For example, EMIVAY, EYOQAL, and BERGAI01 are identified as the top three selective MOFs based on the Dreiding. EYOQAL is the first, EMIVAY is the second, and BERGAI01 is the third MOF in the selectivity ranking of UFFbased simulations. Similarly, 8 MOFs are common in the promising material list for $\mathrm{CO}_{2} / \mathrm{N}_{2}$ separation. Ranking of the first $4 \mathrm{MOF}$ is very similar in both lists. For instance, KEYFIF01 and KEYFIF are the first and the second materials in both rankings. The third and fourth MOFs, EMIVAY and EYOQAL, identified based on the Dreiding only change their places as the fourth and third in the UFF-based list. All MOFs except one are the same in $\mathrm{CO}_{2} / \mathrm{CH}_{4}$ selectivity rankings. Rankings of top 5 MOFs for $\mathrm{CO}_{2} / \mathrm{CH}_{4}$ selectivity are very similar. For instance, KEYFIF has the second highest selectivity in both lists. The first and the third MOFs according to Dreiding results are KEYFIF01 and GIWNUV, and they are the third and first MOF, respectively, in the UFF-based list. The numbers of identical MOFs in top 10 rankings based on molecular simulations employing different FFs are also tabulated in Table S2. The high number of common MOFs that appear in both lists indicate that Dreiding and UFF predict similar selectivity ranking of MOFs, supporting the further use of these two generic FFs in high-throughput screening studies to identify the most selective adsorbents for $\mathrm{CO}_{2}$ separations.

The most promising 10 MOFs based on the $\mathrm{CO}_{2}$ working capacities are also given in Table 4 . There are 6,6 , and 8 common MOFs in the Dreiding and UFF lists for $\mathrm{CO}_{2} / \mathrm{H}_{2}$, $\mathrm{CO}_{2} / \mathrm{N}_{2}$, and $\mathrm{CO}_{2} / \mathrm{CH}_{4}$ separations, respectively. Rankings of the top 3 MOFs are very similar for $\mathrm{CO}_{2} / \mathrm{H}_{2}$, and the top 2 MOFs are the same for $\mathrm{CO}_{2} / \mathrm{N}_{2}$. Although $8 \mathrm{MOFs}$ are common in the list, their rankings are quite different for $\mathrm{CO}_{2} /$
$\mathrm{CH}_{4}$ separation. For example, the tenth MOF in the list of Dreiding is the first MOF in the UFF list. This result supports the lowest $R^{2}$ value between the predicted performance metrics of Dreiding and UFF for the $\mathrm{CO}_{2}$ working capacity of $\mathrm{CO}_{2} /$ $\mathrm{CH}_{4}$ mixture as shown in Table 3. There are 8,7 , and 7 common MOFs in the Dreiding and UFF lists for $S_{\text {sp }}$ rankings of MOFs for $\mathrm{CO}_{2} / \mathrm{H}_{2}, \mathrm{CO}_{2} / \mathrm{N}_{2}$, and $\mathrm{CO}_{2} / \mathrm{CH}_{4}$ separations, respectively. The first two MOFs for $\mathrm{CO}_{2} / \mathrm{H}_{2}$ mixture and top 5 (4) MOFs for $\mathrm{CO}_{2} / \mathrm{N}_{2}\left(\mathrm{CO}_{2} / \mathrm{CH}_{4}\right)$ mixture are the same in both lists. Here, it is important to note that although the $S_{\mathrm{sp}}$ rankings have many common MOFs, there are significant quantitative differences in $S_{\mathrm{sp}}$ values of the top promising MOFs identified by Dreiding and UFF. Seven out of the top 10 MOFs for regenerability ranking are identical for $\mathrm{CO}_{2} / \mathrm{H}_{2}$ separation. The top $3 \mathrm{MOFs}$ identified in the Dreiding-based simulations rank as first, fifth, and tenth in the UFF-based list. Although 8 of the top 10 MOFs are common in both lists for $\mathrm{CO}_{2} / \mathrm{N}_{2}$ separation, their rankings are different. For example, the top 4 MOFs in the Dreiding-based list are fifth, seventh, second, and first in the list of UFF. Finally, there are 8 identical MOFs in the regenerability lists for $\mathrm{CO}_{2} / \mathrm{CH}_{4}$ separations. The first, sixth, eighth, and tenth of the top $10 \mathrm{MOF}$ in the Dreiding list have the same rankings with the UFF list. Since these top MOFs have not been experimentally tested for $\mathrm{CO}_{2}$ separations to the best of our knowledge, we are not able to make a comparison between experimentally measured and simulated performance evaluation metrics. The good agreement between experimentally measured and predicted $\mathrm{CO}_{2} / \mathrm{H}_{2}$, $\mathrm{CO}_{2} / \mathrm{N}_{2}$, and $\mathrm{CO}_{2} / \mathrm{CH}_{4}$ selectivities of various MOFs was shown in Figure S1, and we believe that our computational approach will make accurate estimates for the selectivities of MOFs which have not been experimentally tested yet. 


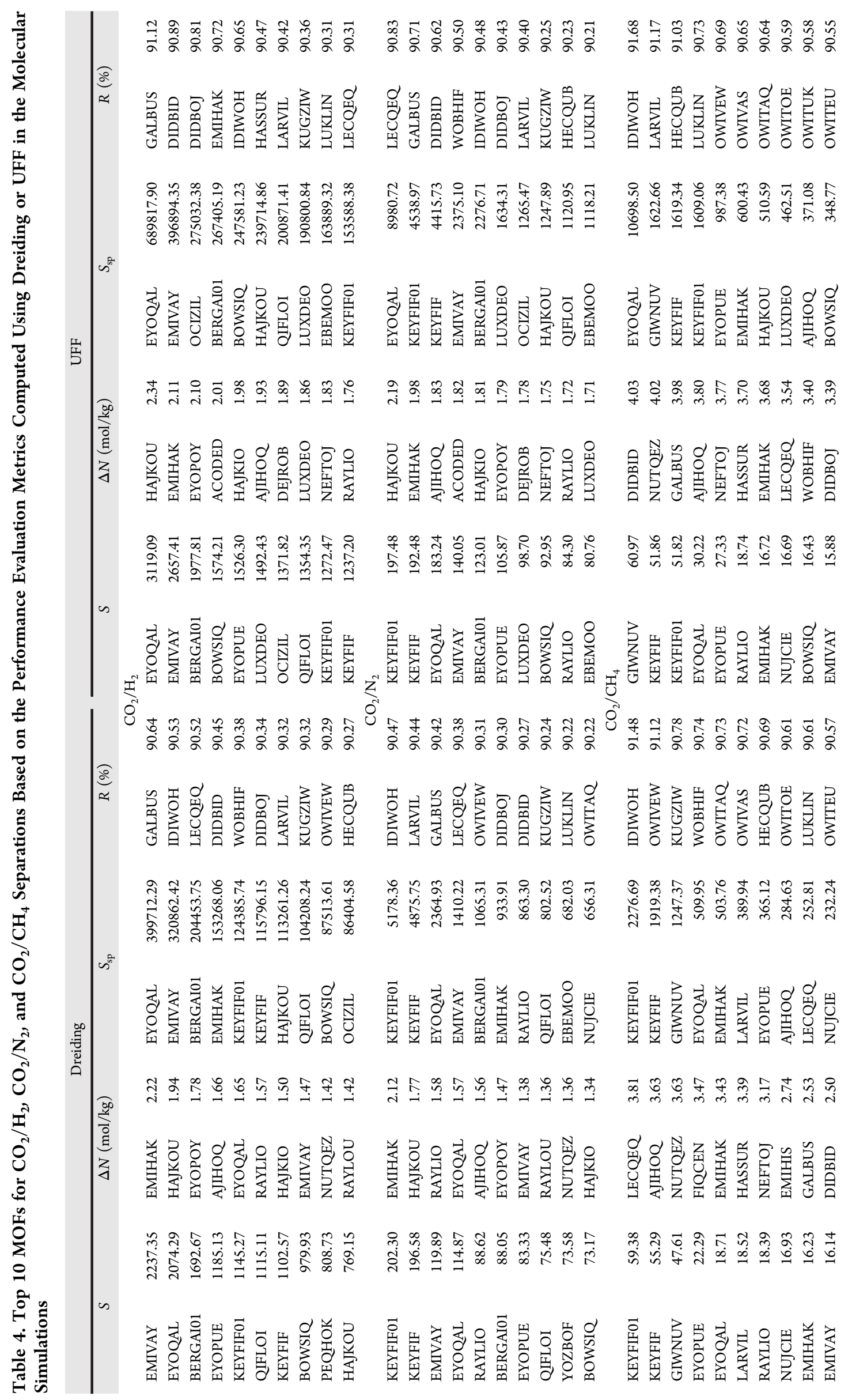



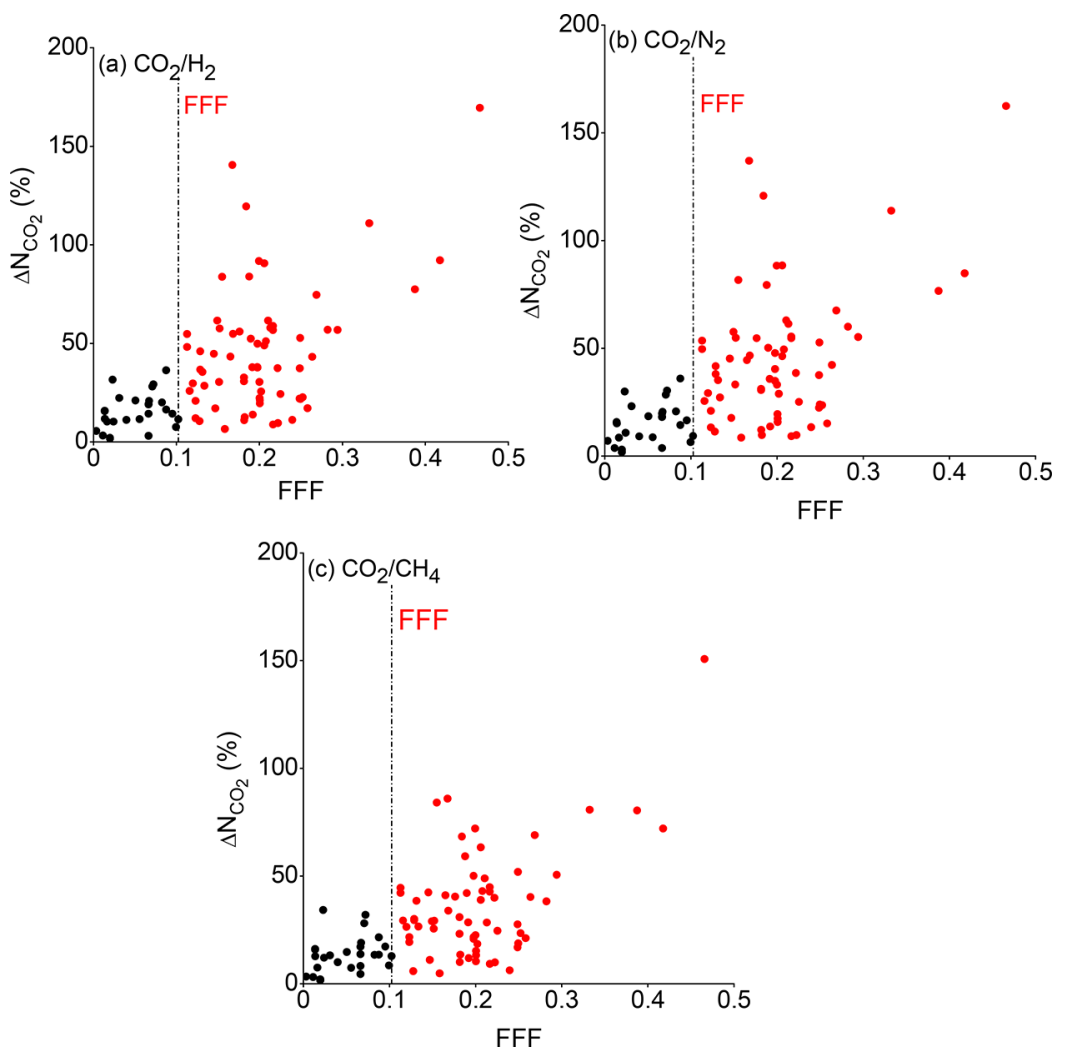

Figure 6. Relation between change in the $\mathrm{CO}_{2}$ uptake and FFF for (a) $\mathrm{CO}_{2} / \mathrm{H}_{2}$, (b) $\mathrm{CO}_{2} / \mathrm{N}_{2}$, and (c) $\mathrm{CO}_{2} / \mathrm{CH}_{4}$ mixtures. The vertical dashed lines are given to differentiate between the MOFs that are sensitive to the FF type (on the right) and the ones that are not sensitive to the FF type (on the left).

In order to quantify the robustness of the ranking of MOFs to the FF selection, we also computed the Spearman's ranking correlation coefficients (SRCC). Values of SRCC change from -1 to 1 and indicate the correlation between two sets of ranking lists. Table S3 shows that SRCC is 0.98, 0.95, 0.97, and 0.96 for $S, \Delta N, S_{\mathrm{sp}}$, and $R \%$, respectively. This analysis suggests that the rankings of 100 MOFs based on the Dreiding FF are positively correlated with those based on the UFF, and strength of the correlation is very high. These results show that either of the generic FF can be safely used to screen and rank MOFs based on the four adsorbent performance evaluation metrics that we considered in this work. Throughout the manuscript, our aim is not to show superiority/accuracy of one generic FF over another but to understand how the ranking of the best MOF adsorbents changes based on the FF type. Results show that adsorbent evaluation metrics quantitatively change due to the differences in the predicted $\mathrm{CO}_{2}$ uptakes of MOFs depending on the FF. In order to provide a guideline for the simulators in selecting either Dreiding or UFF, we proposed a simple factor that assesses sensitivity of the $\mathrm{CO}_{2}$ uptake to the FF type. With this factor, we aim to differentiate between the MOFs for which using either Dreiding or UFF does not make any significant difference in the predicted $\mathrm{CO}_{2}$ uptakes and the MOFs for which the type of the FF plays an important role in predicting the $\mathrm{CO}_{2}$ uptakes and separation performance of the materials. The force field factor (FFF) was defined using the energy parameters of atoms in the Dreiding and UFF. Almost all atoms have different energy and size parameters $\left(\varepsilon / k_{\mathrm{B}}\right.$ and $\sigma$, respectively) in each FF. For example, carbon is available in all MOFs, its $\varepsilon$ and $\sigma$ parameters are $47.89 \mathrm{~K}$ and $3.47 \AA$ in Dreiding, whereas $52.87 \mathrm{~K}$ and $3.43 \AA$, respectively in the UFF.
The FFF that we propose consists of energy parameters since adsorption mainly depends on the energetic interactions, the type and the number of atoms of the MOFs:

$$
\begin{aligned}
& \mathrm{FFF}= \\
& \frac{\left|\sum_{i}^{N} n_{i} \times \frac{n_{i}}{N} \times \varepsilon_{i, \text { Dreiding }} / k_{\mathrm{B}}-\sum_{i}^{N} n_{i} \times \frac{n_{i}}{N} \times \varepsilon_{i, \mathrm{UFF}} / k_{\mathrm{B}}\right|}{\sum_{i}^{N} n_{i} \times \frac{n_{i}}{N} \times \varepsilon_{i, \text { Dreiding }} / k_{\mathrm{B}}}
\end{aligned}
$$

Here, $n_{i}$ is the number of atoms $i, N$ is the total number of atoms of $\mathrm{MOF}$, and $\varepsilon_{i} / k_{\mathrm{B}}$ is the energy parameter of the atom $i$. This term expresses how much the potential parameter changes when the UFF was used instead of the Dreiding. We examined the relation between the FFF and the changes in the predicted $\mathrm{CO}_{2}$ uptakes of MOFs. The latter was defined as follows where the $\mathrm{CO}_{2}$ uptake predicted by the Dreiding was taken as the reference:

$$
\Delta N_{\mathrm{CO}_{2}} \%=\mid N_{\mathrm{CO}_{2}, \text { Dreiding }}-N_{\mathrm{CO}_{2}, \mathrm{UFF}} \mathrm{I} / N_{\mathrm{CO}_{2}, \text { Dreiding }} \times 100
$$

Figure 6 shows $\Delta N_{\mathrm{CO}_{2}} \%$ as a function of the FFF for the MOFs. Black points in each figure represent the MOFs for which the predicted $\mathrm{CO}_{2}$ uptakes by two different FF vary less than $35 \%$. In fact, $24 \mathrm{MOFs}$ have less than $25 \%$ change in their $\mathrm{CO}_{2}$ uptakes for $\mathrm{CO}_{2} / \mathrm{H}_{2}, \mathrm{CO}_{2} / \mathrm{N}_{2}$, and $\mathrm{CO}_{2} / \mathrm{CH}_{4}$ mixtures. The FFF of MOFs shown with black points in Figure 6 are less than 0.1 , and their average FFF is 0.05 . These are the MOFs that are not sensitive to the FF type. In other words, the area at the left of the vertical dashed lines shown in Figure 6 shows the safe zone to the simulators, where predictions for the $\mathrm{CO}_{2}$ 
uptake of MOFs would not significantly change depending on the FF used in molecular simulations. For example, EMIHAK has the lowest FFF, 0.003 . Due to its low FFF, the $\Delta N_{\mathrm{CO}_{2}} \%$ values for this MOF are low: 5, 7 and $3 \%$ for $\mathrm{CO}_{2} / \mathrm{H}_{2}, \mathrm{CO}_{2} / \mathrm{N}_{2}$, and $\mathrm{CO}_{2} / \mathrm{CH}_{4}$ mixtures, respectively. The $\mathrm{CO}_{2} / \mathrm{H}_{2}, \mathrm{CO}_{2} / \mathrm{N}_{2}$, and $\mathrm{CO}_{2} / \mathrm{CH}_{4}$ selectivities of EMIHAK predicted from Dreiding are 704.52, 55.12, and 16.23, respectively, and these are very similar to the ones predicted by UFF, 636.46, 50.15, and 16.72. On the basis of the working capacity rankings, EMIHAK is the first MOF in the Dreiding list and second MOF in the UFF list for $\mathrm{CO}_{2} / \mathrm{H}_{2}$ and $\mathrm{CO}_{2} / \mathrm{N}_{2}$ mixtures and is the fifth $\mathrm{MOF}$ in the Dreiding list and seventh MOF in the UFF list for $\mathrm{CO}_{2} / \mathrm{CH}_{4}$. This result shows that ranking of the MOFs having low FFF is not significantly affected from the FF.

Figure 6 shows that if the FFF is computed to be higher than 0.1 , then Dreiding and UFF are expected to make different predictions for the $\mathrm{CO}_{2}$ uptakes of MOFs, which also means that ranking of MOF adsorbents for $\mathrm{CO}_{2}$ separations may be different. Red points in Figure 6 represent the MOFs for which the two FFs make different estimates for the $\mathrm{CO}_{2}$ uptake. Most MOFs have more than $40 \%$ change in the $\mathrm{CO}_{2}$ uptakes and their average FFF is 0.203 . For example, LUXDEO has a high FFF, 0.42 leading to very high $\Delta N_{\mathrm{CO}_{2}} \%$ values of 92,85 , and $72 \%$ for $\mathrm{CO}_{2} / \mathrm{H}_{2}, \mathrm{CO}_{2} / \mathrm{N}_{2}$, and $\mathrm{CO}_{2} / \mathrm{CH}_{4}$ mixtures, respectively. As a result, its performance evaluation metrics significantly change depending on the FF. For example, $\mathrm{CO}_{2} /$ $\mathrm{H}_{2}$ selectivity of LUXDEO was predicted to be 695 by the Dreiding and 1492 by the UFF. LUXDEO was in the highly selective MOF lists determined by the UFF but it did not appear in the Dreiding list. At that point, it is important to note that not all the MOFs having FFF $>0.1$ have high $\Delta N_{\mathrm{CO}_{2}} \%$ as can be seen from Figure 6. There are several MOFs with FFF of $0.1-0.25$, and half of them have low $\Delta N_{\mathrm{CO}_{2}} \%$. However, MOFs with FFFs $>0.3$ are the ones that show the highest deviations between Dreiding and UFF predictions for the $\mathrm{CO}_{2}$ uptake. Therefore, it is better to use the FFF to quantitatively define the safe region: If the FFF is less than 0.1, then either the Dreiding or the UFF can be used to evaluate the $\mathrm{CO}_{2}$ uptake and adsorption-based $\mathrm{CO}_{2}$ separation potential of MOFs.

It is also a good practice to examine why low (high) FFF leads to small (large) changes in the $\mathrm{CO}_{2}$ uptakes. We defined the FFF to show the change in the potential parameters of atoms. For example, OWITIY has the second lowest FFF, 0.01. This MOF has Mn, and since its energy parameter is not available in Dreiding, it was taken from the UFF. Therefore, there is no difference for the $\varepsilon / k_{\mathrm{B}}$ of metal atoms. The energy parameters of $144 \mathrm{C}$ and $52 \mathrm{H}$ atoms increased from 47.88 to $52.87 \mathrm{~K}$ and 7.65 to $22.15 \mathrm{~K}$, respectively, when the UFF was used instead of the Dreiding. However, this increase was balanced by the decrease in the energy parameters of $96 \mathrm{O}$ atoms from 48.19 to $30.21 \mathrm{~K}$. As a result, the FFF is small for that MOF. In other words, the increase in the energy parameters of $(\mathrm{C}+\mathrm{H})$ is balanced with the decrease in energy parameters of $(\mathrm{N}+\mathrm{O})$ for the MOFs having low FFFs. In contrast, MOFs with high FFFs are either those having a metal atom which shows a large change when the FF is switched from Dreiding to UFF (such as OFERUN) or those having a large number of $\mathrm{C}$ and $\mathrm{H}$ atoms in their structures (such as GUPCOK). In the case of OFERUN, the energy parameter of $\mathrm{Zn}$ significantly increases when the UFF was used and leads to a high FFF of 0.39 . GUPCOK has large number of $\mathrm{C}$ and $\mathrm{H}$ atoms, and the UFF part of the eq 1 dominates the Dreiding part and leads to a large FFF of 0.46 for that MOF. Supporting this argument, the average of ratio of sum of $\mathrm{C}$ and $\mathrm{H}$ atoms to the total number of atoms in MOFs is 0.76 for the MOFs having high FFF whereas it is 0.62 for the MOFs having low FFFs. Atoms type and numbers of the MOFs having the five lowest and highest FFFs are also given in Table S4.

Finally, it is important to note that we aim to arbitrarily define a simple parameter that can be very quickly calculated before the molecular simulations to make a decision of using either Dreiding or UFF. Several other factors which affect the adsorption strength of the gases in the MOFs such as topology of the material, pore size, and pore shape have not been considered in the definition of FFF. The usefulness of the FFF is the following: Before computationally demanding simulations, one can calculate the FFF within seconds only considering the number and type of the atoms present in the MOF. If this value is smaller than 0.1 , then either of the generic FFs can be used, since they will give similar estimates for $\mathrm{CO}_{2}$ uptakes of MOFs and hence similar rankings of the MOF adsorbents. However, we would like to reiterate that having a low FFF does not mean that either Dreiding or UFF are necessarily accurate for this MOF, it just means that they are interchangeable. There may be cases that the best thing to do would be to use neither and develop a new model. If the FFF is higher than 0.1, significant quantitative differences can be expected for the $\mathrm{CO}_{2}$ predictions of the Dreiding and UFF. In this case, obtaining experimental data to validate the selection of the FF or performing more detailed quantum-level calculations can be considered since the MOF is sensitive to the FF type.

\section{CONCLUSION}

This study examined the impact of the FF selection on highthroughput computational screening of MOFs for $\mathrm{CO}_{2} / \mathrm{H}_{2}$, $\mathrm{CO}_{2} / \mathrm{N}_{2}$, and $\mathrm{CO}_{2} / \mathrm{CH}_{4}$ separations. We performed molecular simulations for $100 \mathrm{MOF}$ using Dreiding and repeated these simulations using UFF to compute adsorption of $\mathrm{CO}_{2} / \mathrm{H}_{2}$, $\mathrm{CO}_{2} / \mathrm{N}_{2}$, and $\mathrm{CO}_{2} / \mathrm{CH}_{4}$ mixtures. Four adsorbent evaluation metrics, selectivity, working capacity, sorbent selection parameter, and regenerability were calculated using the results of Dreiding and UFF-based simulations and they were compared. Results showed that while there are quantitative differences in the computed metrics, ranking of MOFs is similar for two different FFs, especially in terms of selectivity and regenerability, which are the key parameters to select the most promising materials. Therefore, it is concluded that both FFs can be used in high-throughput molecular simulations of MOFs to identify the useful materials for adsorption-based $\mathrm{CO}_{2}$ separations. We also defined a FFF and showed its relation with the change in $\mathrm{CO}_{2}$ uptakes of MOFs to guide the simulators. If the FFF value of a MOF is lower than 0.1, then the role of the $\mathrm{FF}$ on the $\mathrm{CO}_{2}$ uptake predictions is negligible; however, if the FFF is higher than 0.3 , then significant quantitative differences in the predicted $\mathrm{CO}_{2}$ uptakes, adsorbent evaluation metrics, and MOF rankings can be observed. With this FFF, the safe region in which the results of molecular simulation do not significantly change depending on the type of generic FF is shown. These results will be of great interest for researchers working on molecular simulations of MOFs by providing insights into choosing the appropriate FF. 


\section{ASSOCIATED CONTENT}

\section{S Supporting Information}

The Supporting Information is available free of charge on the ACS Publications website at DOI: 10.1021/acs.iecr.7b04792.

Potential parameters of the MOF atoms in UFF and Dreiding; number of common MOFs in top 10 material rankings based on molecular simulations performed using Dreiding and UFF; Spearman's ranking correlation coefficient (SRCC) between Dreiding-based and UFFbased rankings of 100 MOFs; five MOFs with the highest and lowest FFFs, comparison of simulation results with the experiments for $\mathrm{CO}_{2} / \mathrm{H}_{2}, \mathrm{CO}_{2} / \mathrm{N}_{2}$, and $\mathrm{CO}_{2} / \mathrm{CH}_{4}$ selectivities of various MOFs; comparison of gas uptakes and $\mathrm{CO}_{2} / \mathrm{H}_{2}, \mathrm{CO}_{2} / \mathrm{N}_{2}$, and $\mathrm{CO}_{2} / \mathrm{CH}_{4}$ selectivities of MOFs calculated with Dreiding and UFF (PDF)

\section{AUTHOR INFORMATION}

\section{Corresponding Author}

*E-mail: skeskin@ku.edu.tr.

\section{ORCID $\odot$}

Seda Keskin: 0000-0001-5968-0336

\section{Notes}

The authors declare no competing financial interest.

\section{ACKNOWLEDGMENTS}

S.K. acknowledges ERC-2017-Starting Grant. This study has received funding from the European Research Council (ERC) under the European Union's Horizon 2020 research and innovation programme (ERC-2017-Starting Grant, grant agreement No. 756489-COSMOS).

\section{REFERENCES}

(1) Furukawa, H.; Cordova, K. E.; O’Keeffe, M.; Yaghi, O. M. The Chemistry and Applications of Metal-Organic Frameworks. Science 2013, 341 (6149), 974-986.

(2) Meek, S. T.; Greathouse, J. A.; Allendorf, M. D. Metal-Organic Frameworks: A Rapidly Growing Class of Versatile Nanoporous Materials. Adv. Mater. (Weinheim, Ger.) 2011, 23 (2), 249-267.

(3) Qiu, S.; Xue, M.; Zhu, G. Metal-Organic Framework Membranes: From Synthesis to Separation Application. Chem. Soc. Rev. 2014, 43 (16), 6116-6140.

(4) Liu, Y.; Wang, Z. U.; Zhou, H. C. Recent Advances in Carbon Dioxide Capture with Metal-Organic Frameworks. Greenhouse Gases: Sci. Technol. 2012, 2 (4), 239-259.

(5) Belmabkhout, Y.; Guillerm, V.; Eddaoudi, M. Low Concentration $\mathrm{CO}_{2}$ Capture Using Physical Adsorbents: Are Metal-Organic Frameworks Becoming the New Benchmark Materials? Chem. Eng. J. (Amsterdam, Neth.) 2016, 296, 386-397.

(6) Keskin, S.; van Heest, T. M.; Sholl, D. S. Can Metal-Organic Framework Materials Play a Useful Role in Large-Scale Carbon Dioxide Separations? ChemSusChem 2010, 3 (8), 879-891.

(7) Li, J.-R.; Ma, Y.; McCarthy, M. C.; Sculley, J.; Yu, J.; Jeong, H.-K.; Balbuena, P. B.; Zhou, H.-C. Carbon Dioxide Capture-Related Gas Adsorption and Separation in Metal-Organic Frameworks. Coord. Chem. Rev. 2011, 255 (15), 1791-1823.

(8) Lu, X.; Jin, D.; Wei, S.; Wang, Z.; An, C.; Guo, W. Strategies to Enhance $\mathrm{CO}_{2}$ Capture and Separation Based on Engineering Absorbent Materials. J. Mater. Chem. A 2015, 3 (23), 12118-12132.

(9) Ben-Mansour, R.; Habib, M.; Bamidele, O.; Basha, M.; Qasem, N.; Peedikakkal, A.; Laoui, T.; Ali, M. Carbon Capture by Physical Adsorption: Materials, Experimental Investigations and Numerical Modeling and Simulations-a Review. Appl. Energy 2016, 161, 225255.
(10) Colon, Y. J.; Snurr, R. Q. High-Throughput Computational Screening of Metal-Organic Frameworks. Chem. Soc. Rev. 2014, 43 (16), 5735-5749.

(11) Jiang, J. W.; Babarao, R.; Hu, Z. Q. Molecular Simulations for Energy, Environmental and Pharmaceutical Applications of Nanoporous Materials: From Zeolites, Metal-Organic Frameworks to Protein Crystals. Chem. Soc. Rev. 2011, 40 (7), 3599-3612.

(12) Bao, Y.; Martin, R. L.; Simon, C. M.; Haranczyk, M.; Smit, B.; Deem, M. W. In Silico Discovery of High Deliverable Capacity Metal Organic Frameworks. J. Phys. Chem. C 2015, 119 (1), 186-195.

(13) Thornton, A. W.; Simon, C. M.; Kim, J.; Kwon, O.; Deeg, K. S.; Konstas, K.; Pas, S. J.; Hill, M. R.; Winkler, D. A.; Haranczyk, M.; Smit, B. Materials Genome in Action: Identifying the Performance Limits of Physical Hydrogen Storage. Chem. Mater. 2017, 29 (7), 2844-2854.

(14) Bordiga, S.; Vitillo, J. G.; Ricchiardi, G.; Regli, L.; Cocina, D.; Zecchina, A.; Arstad, B.; Bjørgen, M.; Hafizovic, J.; Lillerud, K. P. Interaction of Hydrogen with MOF-5. J. Phys. Chem. B 2005, 109, 18237-18242.

(15) Sagara, T.; Klassen, J.; Ganz, E. Computational Study of Hydrogen Binding by Metal-Organic Framework-5. J. Chem. Phys. 2004, 121 (24), 12543-12547.

(16) Yang, Q.; Zhong, C. Molecular Simulation of Adsorption and Diffusion of Hydrogen in Metal-Organic Frameworks. J. Phys. Chem. B 2005, 109 (24), 11862-11864.

(17) Yang, Q.; Zhong, C. Understanding Hydrogen Adsorption in Metal-Organic Frameworks with Open Metal Sites: A Computational Study. J. Phys. Chem. B 2006, 110 (2), 655-658.

(18) Rappe, A. K.; Casewit, C. J.; Colwell, K. S.; Goddard, W. A.; Skiff, W. M. UFF, a Full Periodic Table Force Field for Molecular Mechanics and Molecular Dynamics Simulations. J. Am. Chem. Soc. 1992, 114, 10024.

(19) Mayo, S. L.; Olafson, B. D.; Goddard, W. A. Dreiding: A Generic Force Field for Molecular Simulations. J. Phys. Chem. 1990, 94 (26), 8897-8909.

(20) McDaniel, J. G.; Li, S.; Tylianakis, E.; Snurr, R. Q.; Schmidt, J. R. Evaluation of Force Field Performance for High-Throughput Screening of Gas Uptake in Metal-Organic Frameworks. J. Phys. Chem. C 2015, 119 (6), 3143-3152.

(21) Dzubak, A. L.; Lin, L. C.; Kim, J.; Swisher, J. A.; Poloni, R.; Maximoff, S. N.; Smit, B.; Gagliardi, L. Ab Initio Carbon Capture in Open-Site Metal-Organic Frameworks. Nat. Chem. 2012, 4 (10), 810816.

(22) Boyd, P. G.; Moosavi, S. M.; Witman, M.; Smit, B. Force-Field Prediction of Materials Properties in Metal-Organic Frameworks. J. Phys. Chem. Lett. 2017, 8 (2), 357-363.

(23) Watanabe, T.; Sholl, D. S. Accelerating Applications of MetalOrganic Frameworks for Gas Adsorption and Separation by Computational Screening of Materials. Langmuir 2012, 28 (40), 14114-14128.

(24) Wu, D.; Yang, Q.; Zhong, C.; Liu, D.; Huang, H.; Zhang, W.; Maurin, G. Revealing the Structure-Property Relationships of MetalOrganic Frameworks for $\mathrm{CO}_{2}$ Capture from Flue Gas. Langmuir 2012, 28 (33), 12094-12099.

(25) Qiao, Z.; Zhang, K.; Jiang, J. In Silico Screening of 4764 Computation-Ready, Experimental Metal-Organic Frameworks for $\mathrm{CO}_{2}$ Separation. J. Mater. Chem. A 2016, 4, 2105-2114.

(26) Sumer, Z.; Keskin, S. Ranking of MOF Adsorbents for CO2 Separations: A Molecular Simulation Study. Ind. Eng. Chem. Res. 2016, 55 (39), 10404-10419.

(27) Keskin, S.; Liu, J.; Rankin, R. B.; Johnson, J. K.; Sholl, D. S. Progress, Opportunities, and Challenges for Applying Atomically Detailed Modeling to Molecular Adsorption and Transport in MetalOrganic Framework Materials. Ind. Eng. Chem. Res. 2009, 48 (5), 2355-2371.

(28) Allen, F. H. The Cambridge Structural Database: A Quarter of a Million Crystal Structures and Rising. Acta Crystallogr., Sect. B: Struct. Sci. 2002, 58 (3), 380-388. 
(29) Frenkel, D.; Smit, B. Understanding Molecular Simulation: From Algorithms to Applications, 2nd ed.; Academic Press: San Diego, CA, 2002.

(30) Greathouse, J. A.; Allendorf, M. D. Force Field Validation for Molecular Dynamics Simulations of IRMOF-1 and Other Isoreticular Zinc Carboxylate Coordination Polymers. J. Phys. Chem. C 2008, 112 (15), 5795-5802.

(31) Haldoupis, E.; Watanabe, T.; Nair, S.; Sholl, D. S. Quantifying Large Effects of Framework Flexibility on Diffusion in MOFs: $\mathrm{CH}_{4}$ and $\mathrm{CO}_{2}$ in ZIF-8. ChemPhysChem 2012, 13 (15), 3449-3452.

(32) Pérez-Pellitero, J.; Amrouche, H.; Siperstein, F. R.; Pirngruber, G.; Nieto-Draghi, C.; Chaplais, G.; Simon-Masseron, A.; Bazer-Bachi, D.; Peralta, D.; Bats, N. Adsorption of $\mathrm{CO}_{2}, \mathrm{CH}_{4}$, and $\mathrm{N}_{2}$ on Zeolitic Imidazolate Frameworks: Experiments and Simulations. Chem. - Eur. J. 2010, 16 (5), 1560-1571.

(33) Sezginel, K. B.; Uzun, A.; Keskin, S. Multivariable Linear Models of Structural Parameters to Predict Methane Uptake in Metal-Organic Frameworks. Chem. Eng. Sci. 2015, 124, 125-134.

(34) Basdogan, Y.; Keskin, S. Simulation and Modelling of MOFs for Hydrogen Storage. CrystEngComm 2015, 17 (2), 261-275.

(35) Potoff, J. J.; Siepmann, J. I. Vapor-Liquid Equilibria of Mixtures Containing Alkanes, Carbon Dioxide, and Nitrogen. AIChE J. 2001, 47 (7), 1676-1682.

(36) Makrodimitris, K.; Papadopoulos, G. K.; Theodorou, D. N. Prediction of Permeation Properties of $\mathrm{CO}_{2}$ and $\mathrm{N}_{2}$ through Silicalite Via Molecular Simulations. J. Phys. Chem. B 2001, 105 (4), 777-788.

(37) Buch, V. Path Integral Simulations of Mixed Para-D2 and Ortho-D2 Clusters: The Orientational Effects. J. Chem. Phys. 1994, 100 (10), 7610-7629.

(38) Martin, M. G.; Siepmann, J. I. Transferable Potentials for Phase Equilibria. 1. United-Atom Description of N-Alkanes. J. Phys. Chem. B 1998, 102 (14), 2569-2577.

(39) Wilmer, C. E.; Kim, K. C.; Snurr, R. Q. An Extended Charge Equilibration Method. J. Phys. Chem. Lett. 2012, 3 (17), 2506-2511.

(40) Li, W.; Rao, Z.; Chung, Y.; Li, S. The Role of Partial Atomic Charge Assignment Methods on the Computational Screening of Metal-Organic Frameworks for $\mathrm{CO}_{2}$ Capture under Humid Conditions. Chemistry Select 2017, 2 (29), 9458-9465.

(41) Bae, Y. S.; Snurr, R. Q. Development and Evaluation of Porous Materials for Carbon Dioxide Separation and Capture. Angew. Chem., Int. Ed. 2011, 50 (49), 11586-11596. 